\title{
Spatio-temporal soil quality assessment under crop rotation irrigated with treated urban wastewater using fuzzy modelling
}

\author{
Marjan Ghaemi ${ }^{1}$, Ali R. Astaraei ${ }^{1}$, Mehdi Nassiri Mahalati ${ }^{2}$, Hojat Emami ${ }^{1}$, and Hossein H. Sanaeinejad ${ }^{3}$ \\ ${ }^{1}$ Department of Soil Sciences, ${ }^{2}$ Department of Agronomy, ${ }^{3}$ Department of Water Engineering, \\ Ferdowsi University of Mashhad (FUM) campus, Azadi Sq., Mashhad, Khorasan Razavi, Iran
}

Received September 14, 2013; accepted April 25, 2014

\begin{abstract}
A b s t r a c t. Quantifying soil quality is important for assessing soil management practices effects on spatial and temporal variability of soil quality at the field scale. We studied the possibility of defining a simple and practical fuzzy soil quality index based on biological, chemical and physical indicators for assessing quality variations of soil irrigated with well water and treated urban wastewater during two experimental years. In this study 6 properties considered as minimum data set were selected out of 18 soil properties as total data set using the principal component analysis. Treated urban wastewater use had greater impact on biological and chemical quality. The results showed that the studied minimum data set could be a suitable representative of total data set. Significant correlation between the fuzzy soil quality index and crop yield $\left(\mathrm{R}^{2}=0.72\right)$ indicated the index had high biological significance for studied area. Fuzzy soil quality index approach $\left(\mathrm{R}^{2}=0.99\right)$ could be effectively utilized as a tool leading to better understanding soil quality changes. This is a first trial of creation of a universal index of soil quality undertaken.

Ke y w o r d s: fuzzy membership functions, principal component analysis, soil quality, treated urban wastewater
\end{abstract}

\section{INTRODUCTION}

In recent decades, crop production systems have received increasing attention for optimizing yields, in conserving soil, water, and energy and protecting the environment. Soil quality is defined as the capacity of a soil to function, within ecosystem and land-use boundaries, to sustain biological activity, maintain environmental quality, and promote plant, animal, and human health (Doran and Parkin, 1994). It varies dramatically with management practices (irrigation water quality). Treated wastewater application improves soil quality, but there are reports of soil quality decline in agricultural soils due to long term application of treated wastewater
(Lee et al., 2006). Therefore, assessment and prediction of soil quality dynamics can provide a better understanding of soil conditions and assist in establishing priorities for soil productivity management practices (Zalidis et al., 2002). There are uncertainties in any evaluation process due to both data and model ambiguity which includes errors in measurement, intrinsic soil variability, soil instability, conceptual ambiguity, over-abstraction, ignoring the key factors that can affect soil quality (McBratney and Odeh, 1997). Fuzzy logic has a useful framework for studying the complexity of soil quality, the uncertainty due to errors in measurement and imprecise boundaries and qualitative knowledge associated with site-specific soil quality evaluation (McBratney and Odeh, 1997). Braimoh et al. (2004) indicated that fuzzy technique is helpful for evaluating slight differences in soil quality. Torbert et al. (2008) considered the possibility of using fuzzy modelling theory as the fuzzy multi-attributive approach for soil quality assessment. They defined a combined fuzzy soil quality index (CFSQI) providing an integrated estimation of soil quality of a given agricultural field. However, weights of soil indicators are not considered in soil quality index calculation. Andrews et al. (2002b) indicated that soil quality indices are the most common methods for soil quality evaluation, due to their ease of use, flexibility and quantification. Therefore, it is possible to define the concept of a fuzzy soil quality index (FSQI) for assessment of soil quality based on fuzzy modelling. The index can be applied to monitor spatial and temporal changes in the soil quality, instead of using the common definitions of soil quality indicators such as soil physical, chemical and biological properties and their processes (Lee et al., 2006). Consequently, the soil quality index should be able to compare 
different management systems for soil quality variations, to evaluate the temporal variability in a given site, to determine a trend and to identify the problems incurred within a field. A comprehensive soil quality index should also be a combination of chemical, physical and biological properties. It is important to develop a simple and effective index for evaluating soil quality (Aparicio and Costa, 2007).

A two year field study was conducted with the following objectives:

- define a fuzzy soil quality index (FSQI) based on biological, chemical and physical indicators for assessing soil quality in a wheat-maize-fallow rotation irrigated with well water and treated urban wastewater,

- select suitable indicators by using principal component analysis (PCA),

- provide a simple and appropriate weighting method for calculating fuzzy soil quality index model,

- evaluate the effect of irrigation management changes on the spatial and temporal variability of soil quality at farm scale, and

- determine the relationship between soil quality index and maize yield.

\section{MATERIALS AND METHODS}

A two year field experiment was carried out at the Astan Quds experimental farm situated in the east of Mashhad (North East of Iran), geographically located between 740460, 749280 and 4005180, 4015680 UTM (Universal Transverse Mercator coordinate system) (Fig. 1). According to the climatic classification of Emberger, the farm is located in arid and semi-arid climate with the mean annual temperature of approximately $14^{\circ} \mathrm{C}$ and mean annual precipitation of about $250 \mathrm{~mm}$. Soils in this area are categorized as Aridisols and Entisols, based on soil taxonomy system.

This experiment was laid out in an 18 ha field with crop rotation of wheat ( $c v$. Falat) - maize ( $c v$. S.C-704) - fallow, irrigated using two different types of water:

- well water for 15 years, and

- treated urban wastewater for the first time. The soil of the experimental field was sampled in a 5 ha study area.

A systematic soil sampling layout was designed using regular grids with $20 \mathrm{~m}$ spacing. At each sampling point, five sub-samples $(0-30 \mathrm{~cm})$ were taken within a grid of $400 \mathrm{~m}^{2}$ to make a composite soil sample (Fig. 1). 125 composite soil

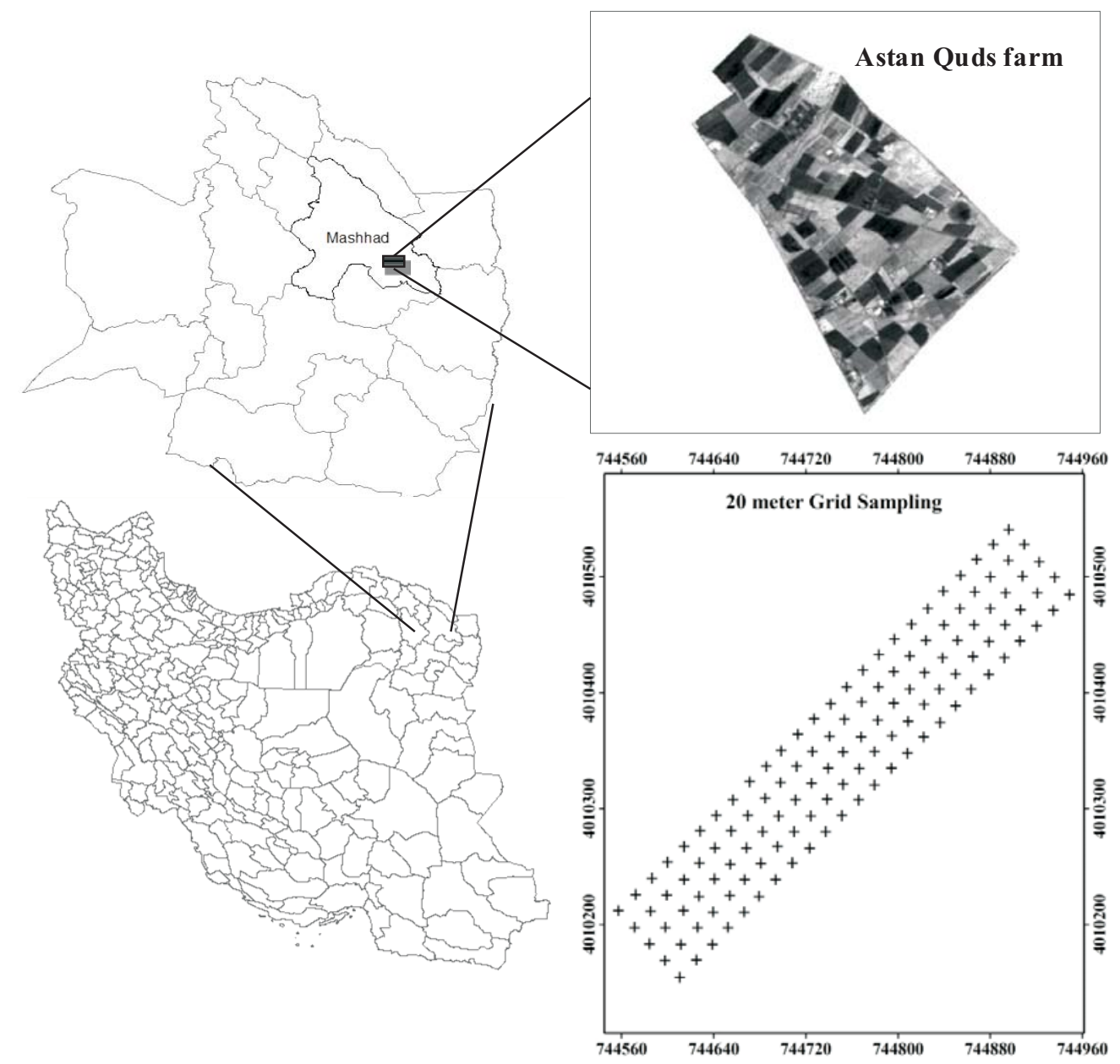

Fig. 1. Geographical location of the studied area with sampling points. 
samples were collected after a fallow period before (presowing) and after the application of treated urban wastewater for wheat-maize rotations during two years $\left(\mathrm{t}_{1}=2011\right.$ 2012 and $\left.t_{2}=2012-2013\right)$. The collected soil samples were airdried, ground and passed through a $2 \mathrm{~mm}$ sieve. Eighteen soil properties (physical, chemical and biological) affecting maize yield and soil quality were determined using standard laboratory procedures. Soil acidity $(\mathrm{pH})$ and electrical conductivity of the saturation extract (EC) were measured in soil extracts (Page et al., 1982). The following chemical measurement procedures were used (Page et al., 1982): organic carbon (OC) by Walkely and Black (1934) method, available phosphorus $(\mathrm{P})$ by extracting samples with sodium bicarbonate solution, available potassium $(\mathrm{K})$ by extracting samples with ammonium acetate solution, total nitrogen $(\mathrm{N})$ by the Kjeldahl method, and microelements ( $\mathrm{Cu}, \mathrm{Mn}, \mathrm{Zn}$ and $\mathrm{Fe}$ ) by diethylene triamine penta acetate (DTPA) extraction (Lindsay and Norvell, 1978). The following physical analyses were carried out (Klute, 1986): soil particle size distribution by the Bouyoucos hydrometer method, available water capacity (AWC) by the difference between 33 and $1500 \mathrm{kPa}$ suction, and bulk density (BD) by the core method.

Fresh soil samples taken for biological properties determination were stored at $4^{\circ} \mathrm{C}$ (Gugino et al., 2009). Three soil biological properties were measured (Page et al., 1982): active carbon (AC) by potassium permanganate oxidation method (Gugino et al., 2009), potentially mineralisable nitrogen (PMN) by potassium chloride extraction (Gugino et al., 2009), and microbial biomass carbon (MBC) by fumigationextraction method (Vance et al., 1987). In this study, EC, pH and soil physical properties were considered to remain the same across time for the soil quality index. In this regard, Safary Sanjany and Hajrasoliha (1995), in a seven-year study, reported slight decrease in soil electrical conductivity and no change in $\mathrm{pH}$ in soils irrigated with treated urban wastewater. Plant samples were taken after harvest in the second year to evaluate the relationship between soil quality index and yield. Plants on one meter running row were harvested and crop yield was estimated for each sampling grid $\left(400 \mathrm{~m}^{2}\right)$. Then, the samples were oven-dried at $60^{\circ} \mathrm{C}$ to reach a constant mass. Finally, yield of each grid was calculated as total plant dry mass $\left(\mathrm{g} \mathrm{m}^{-2}\right)$.

Descriptive statistics including mean, minimum and maximum values, standard deviation (SD) and coefficient of variation $(\mathrm{CV})$ were determined for each soil property using SAS software. Selecting representative indicators is of key concern in soil quality evaluation. Ideally, these indicators should cover a wide range of soil properties and each should affect soil quality directly. In this study, the total data set (TDS) consisted of eighteen soil properties (physical, chemical and biological) that were identified as indicators affecting soil quality in various scientific literatures.
The principal component analysis (PCA) was used to select a representative minimum data set (MDS) affecting soil quality (Doran and Parkin, 1994). Standardized principal component analysis (PCA) was performed on the correlation matrix as proposed by Andrews et al. (2002b) and Govaerts et al. (2006), and principal components (PC) with Eigenvalues $\geq 1$ were included in MDS. Then for each $\mathrm{PC}$, variables with weighted factor loading that fell within $10 \%$ of the highest weighted loading were chosen as the most appropriate indicators for the MDS. To reduce redundancy among the highly weighted loading of variables, Pearson correlation coefficients were used for variables within each PC (Andrews and Carroll, 2001).

After selection of representative MDS, the weight for each indicator in TDS and MDS collections which were used for determination of FSQI index was assigned by two methods including the coefficient of variation method $(\mathrm{CV})$, since it is quite simple and practical, and standardized factor analysis (FA) based on its communality (Shukla et al., 2006). According to $C V$ method, the variables with greater variability in the field $(\mathrm{CV})$ should receive a higher weight in a linear model including all soil indicators:

$$
\lambda_{i}=C V_{i} / \Sigma C V_{i}
$$

where: $\lambda_{i}$ is the weight for each variable and $C V_{i}$ is the corresponding coefficient of variation.

In FA method, the communality of each indicator was calculated and then the ratio of its communality to cumulative communality of all indicators was considered as weight of each indicator (Shukla et al., 2006).

To express the studied indicators as a grade of perfection, a fuzzy set methodology was employed in soil quality index calculation. A fuzzy set may be defined as:

$$
A=\left\{x, \mu_{A}(x)\right\} x \in X,
$$

where: $X=\{\mathrm{x}\}$ is a finite set of phenomena, $\mu_{A}(x)$ is a membership function of $X$ for subset $A$ (Zadeh, 1965). Fuzzy membership functions were generated for soil indicators that are important in agricultural land use of the study area by using the Semantic Import (SI) model. In this approach, each variable value is converted to degrees of membership (from 0 to 1 ), according to expert knowledge based on experience or conventional definitions (McBratney and Odeh, 1997). The membership function values of soil indicators were combined using a convex combination function. Accordingly, the joint membership function of all indicators under consideration, defined as fuzzy soil quality index (FSQI), was computed as follows:

$$
F S Q I=\sum_{i=1}^{n} \lambda_{i} M F\left(x_{i}\right)
$$

where: $\lambda_{i}$ is the weight assigned to each indicator, $\operatorname{MF}\left(x_{i}\right)$ is the membership grade and $n$ is the number of indicators. 
T a b l e 1. Membership functions and range values of chemical, physical and biological properties of studied soil

\begin{tabular}{|c|c|c|c|c|c|c|}
\hline \multirow[t]{2}{*}{ Variables } & \multirow[t]{2}{*}{ Model type } & \multicolumn{4}{|c|}{ Membership function parameters } & \multirow{2}{*}{$\begin{array}{l}\text { Source of threshold/ } \\
\text { Membership function }\end{array}$} \\
\hline & & $\alpha$ & $\beta$ & $\gamma$ & & \\
\hline $\mathrm{OC}(\%)$ & \multirow{6}{*}{ Sigma } & 0.5 & 1.68 & 3 & & Torbert et al. (2008) \\
\hline $\mathrm{K}\left(\mathrm{mg} \mathrm{kg}^{-1}\right)$ & & 160 & 205 & 250 & & $\begin{array}{l}\text { Mallarino et al. (2003), } \\
\text { Gugino et al. (2009) }\end{array}$ \\
\hline $\operatorname{MBC}\left(\mathrm{mg} \mathrm{kg}^{-1}\right)$ & & 0 & 150 & 300 & & Masto et al. (2007) \\
\hline $\operatorname{PMN}\left(\mu \mathrm{g} \mathrm{kg}^{-1}\right)$ & & 5 & 10 & 15 & & Gugino et al. (2009) \\
\hline $\mathrm{AC}\left(\mathrm{mg} \mathrm{kg}^{-1}\right)$ & & 150 & 600 & 1050 & & Gugino et al. (2009) \\
\hline \multirow[t]{2}{*}{$\operatorname{AWC}\left(\mathrm{cm}^{3} \mathrm{~cm}^{-3}\right)$} & & 0.04 & 0.17 & 0.3 & & Gugino et al. (2009) \\
\hline & & a & $\mathrm{b}$ & $\mathrm{c}$ & d & \\
\hline $\mathrm{pH}$ & & 5.4 & 6.3 & 7.2 & 7.7 & Gugino et al. (2009) \\
\hline $\left.\mathrm{EC}(\mathrm{dS} \mathrm{m})^{-1}\right)$ & & 0 & 0.5 & 2 & 10 & Glover et al. (2000) \\
\hline $\mathrm{P}\left(\mathrm{mg} \mathrm{kg}^{-1}\right)$ & & 6 & 12 & 20 & 50 & $\begin{array}{l}\text { Tisdale et al. (1993), } \\
\text { Gugino et al. (2009) }\end{array}$ \\
\hline $\mathrm{N}(\%)$ & & 0.05 & 0.25 & 0.5 & 0.8 & $\begin{array}{l}\text { Hazelton and Murphy (2007), } \\
\text { Mohammadrezaei et al. (2012) }\end{array}$ \\
\hline $\mathrm{Fe}\left(\mathrm{mg} \mathrm{kg}^{-1}\right)$ & Irapezoidal & 2 & 10 & 25 & 40 & Malakouti and Tehrani (1999) \\
\hline $\operatorname{Mn}\left(\mathrm{mg} \mathrm{kg}^{-1}\right)$ & & 5 & 9 & 30 & 50 & Malakouti and Tehrani (1999) \\
\hline $\mathrm{Zn}\left(\mathrm{mg} \mathrm{kg}^{-1}\right)$ & & 0.5 & 2 & 6 & 8 & Lindsay and Norvell (1978) \\
\hline $\mathrm{Cu}\left(\mathrm{mg} \mathrm{kg}^{-1}\right)$ & & 0.1 & 0.5 & 2 & 4 & Lindsay and Norvell (1978) \\
\hline \multirow[t]{2}{*}{$\mathrm{BD}\left(\mathrm{Mg} \mathrm{m}^{-3}\right)$} & & 0.7 & 0.9 & 1.4 & 1.6 & Hao et al. (2008) \\
\hline & & $\alpha$ & $\mathrm{m}$ & $\gamma$ & & \\
\hline Sand $(\%)$ & & 0 & 40 & 80 & & Braimoh et al. (2004) \\
\hline Silt (\%) & Gaussian & 0 & 35 & 70 & & Braimoh et al. (2004) \\
\hline Clay (\%) & & 0 & 25 & 50 & & Braimoh et al. (2004) \\
\hline
\end{tabular}

Lower threshold $(\mathrm{a}, \alpha)$, lower baseline $(\beta)$, upper threshold $(\mathrm{d}, \gamma)$, optimal $(\mathrm{b}, \mathrm{c}, \mathrm{m})$. OC - organic carbon, MBC - microbial biomass carbon, $\mathrm{PMN}$ - potentially mineralisable nitrogen, $\mathrm{AC}$ - active carbon, AWC - available water capacity, EC - electrical conductivity, $\mathrm{BD}$ - bulk density.

Table 1 lists fuzzy membership functions and range values for soil indicators used to compute fuzzy soil quality index in TDS and MDS methods. Fuzzy indicators calculations were done based on scripts written in MATLAB used by the author (Mathworks Inc., 2004).

After scoring and weighting the indicators, the estimated $F S Q I_{C V}$ was compared to $F S Q I_{F A}$ for validation. FSQI indices were calculated using TDS and MDS. Regression analysis was performed to determine the MDS efficiency as representative of TDS. Soil physical, chemical and biological quality was assessed by FSQI calculation based on soil physical, chemical and biological indicators, respectively. The relationships among all soil quality indices and maize yield were then determined to obtain the optimum regression model. For ranking soil quality classification based on soil quality effect on plant growth, fuzzy soil quality index was divided into five classes (class I = very high quality to class $\mathrm{V}=$ very low quality) (Gugino et al., 2009). The relative change in FSQI ( $\triangle F S Q I)$ between two soil sampling times was computed as follows:

$$
\Delta F S Q I=\frac{F S Q I t_{2}-F S Q I t_{1}}{F S Q I t_{1}} 100 .
$$

Ordinary kriging method was used to map the spatial distribution of fuzzy soil quality index and its changes over time as classes with continuous values (Yang et al., 2007). The analysis was conducted using the geostatistical analyst extension of ArcGIS 9.2. This method is used for spatial and temporal soil quality indices changes in studying treated urban wastewater impacts. 


\section{RESULTS AND DISCUSSION}

Descriptive statistics of soil properties measured at two sampling times (Table 2) indicate a high variability of soil indicators following Wilding (1985) classification (soil properties with $C V$ more than $35 \%$ have high variability). Minimum and maximum $C V$ were recorded for $\mathrm{pH}(3.1 \%)$ and $\mathrm{Mn}(47.73 \%)$, respectively (Table 2 ).

As shown in Table 2, cultivation effects and treated urban wastewater application during two growing seasons played a greater role on soil biological properties following wheat-maize cultivation irrigated with treated urban wastewater. Hence, it is essential to study soil biological indicators for soil quality evaluation because of their important role in crop growth and improving soil nutrients status (Glover et al., 2000). Active carbon is an indicator of the fraction of soil organic matter that is readily available as a carbon and energy source for the soil microbial community (Gugino et al., 2009). The research by those authors showed that active carbon is a good indicator of soil quality response to changes in crop and soil management, usually responding to management practices much faster than total soil organic carbon. Farming practices and their effects on soil organic matter decomposition and plant uptake can reduce minimum values of organic carbon and major soil nutrients (Gugino et al., 2009). However, larger mean and maximum values of major and minor soil nutrients illustrate the positive role of treated urban wastewater application; similar results was reported by Feizi (2001). Soil with higher nutrient contents after fallow period has better quality for next growing season crop. In this study, soil quality indices were calculated for the TDS and MDS indicators selected using principal component analysis (PCA) (Table 3). Table 3 shows that variables can be grouped into statistical components based

T a b l e 2. Descriptive statistics of soil chemical, physical and biological properties for two sampling times

\begin{tabular}{|c|c|c|c|c|c|c|c|c|}
\hline \multirow{2}{*}{ Variables } & \multicolumn{4}{|c|}{$\mathrm{t}_{1}$} & \multicolumn{4}{|c|}{$\mathrm{t}_{2}$} \\
\hline & Min & Max & Mean & $C V$ & Min & Max & Mean & $C V$ \\
\hline \multicolumn{9}{|c|}{ Chemical properties } \\
\hline $\mathrm{EC}\left(\mathrm{dS} \mathrm{m} \mathrm{m}^{-1}\right)$ & 1.13 & 3.82 & 2.28 & 40.66 & - & - & - & - \\
\hline $\mathrm{pH}$ & 7.21 & 7.95 & 7.55 & 3.10 & - & - & - & - \\
\hline OC (\%) & 0.31 & 1.52 & 0.89 & 34.71 & 0.27 & 1.60 & 0.95 & 36.50 \\
\hline $\mathrm{P}\left(\mathrm{mg} \mathrm{kg}^{-1}\right)$ & 5.21 & 28.68 & 17.59 & 41.45 & 4.44 & 26.99 & 16.91 & 35.28 \\
\hline $\mathrm{K}\left(\mathrm{mg} \mathrm{kg}^{-1}\right)$ & 201.11 & 459.68 & 331.88 & 27.27 & 172.38 & 430.95 & 320.17 & 23.40 \\
\hline $\mathrm{N}(\%)$ & 0.03 & 0.153 & 0.09 & 40.40 & 0.027 & 0.18 & 0.10 & 38.24 \\
\hline $\mathrm{Fe}\left(\mathrm{mg} \mathrm{kg}^{-1}\right)$ & 1.56 & 3.72 & 2.78 & 23.84 & 1.94 & 4.46 & 3.34 & 22.73 \\
\hline $\mathrm{Cu}\left(\mathrm{mg} \mathrm{kg}^{-1}\right)$ & 0.91 & 2.28 & 1.62 & 23.30 & 1.86 & 3.37 & 2.59 & 14.98 \\
\hline $\operatorname{Mn}\left(\mathrm{mg} \mathrm{kg}^{-1}\right)$ & 2.13 & 13.34 & 6.95 & 47.74 & 2.83 & 13.66 & 7.35 & 44.94 \\
\hline $\mathrm{Zn}\left(\mathrm{mg} \mathrm{kg}^{-1}\right)$ & 0.50 & 2.38 & 1.13 & 47.25 & 0.65 & 3.10 & 1.51 & 47.39 \\
\hline \multicolumn{9}{|c|}{ Biological properties } \\
\hline $\mathrm{AC}\left(\mathrm{mg} \mathrm{kg}^{-1}\right)$ & 214.46 & 594.65 & 443.41 & 24.38 & 273.50 & 662.90 & 505.91 & 22.35 \\
\hline $\mathrm{PMN}\left(\mu \mathrm{gN} \mathrm{g}^{-1}\right)$ & 1.60 & 7.30 & 5.24 & 31.59 & 2.20 & 7.90 & 5.79 & 29.06 \\
\hline $\operatorname{MBC}\left(\mathrm{mg} \mathrm{kg}^{-1}\right)$ & 43.68 & 247.92 & 144.52 & 43.36 & 96.38 & 351.84 & 205.95 & 35.90 \\
\hline
\end{tabular}

Physical properties

\begin{tabular}{lccccccc} 
Clay (\%) & 4.27 & 24.72 & 15.36 & 36.19 & - & - & - \\
Silt (\%) & 40.00 & 58.00 & 48.62 & 8.43 & - & - & - \\
Sand (\%) & 29.28 & 43.28 & 36.02 & 8.77 & - & - & - \\
AWC $\left(\mathrm{cm}^{3} \mathrm{~cm}^{-3}\right)$ & 0.13 & 0.21 & 0.16 & 14.31 & - & - & - \\
BD $\left(\mathrm{Mg} \mathrm{m}^{-3}\right)$ & 1.32 & 1.55 & 1.43 & 4.84 & - & - & - \\
\hline
\end{tabular}

$\mathrm{t}_{1}$ - first soil sampling time before application of treated urban wastewater, $\mathrm{t}_{2}-$ second soil sampling time after application of treated urban wastewater in second year, $C V$ - coefficient of variation method. Explanations as in Table 1. 
T a b l e 3. Selection of minimum data set (MDS) through principal component analysis

\begin{tabular}{|c|c|c|c|c|c|}
\hline Components & $\mathrm{PC}_{1}$ & $\mathrm{PC}_{2}$ & $\mathrm{PC}_{3}$ & $\mathrm{PC}_{4}$ & $\mathrm{COM}$ \\
\hline Eigenvalue & 7.742 & 1.927 & 1.304 & 1.161 & \\
\hline$\%$ of variance & 43.015 & 10.707 & 7.249 & 6.455 & \\
\hline Cumulative (\%) & 43.015 & 53.722 & 60.971 & 67.426 & \\
\hline \multicolumn{6}{|c|}{ Factor loading/eigenvector variables } \\
\hline $\mathrm{pH}$ & 0.218 & -0.154 & 0.123 & 0.122 & 0.449 \\
\hline $\mathrm{EC}\left(\mathrm{dS} \mathrm{m} \mathrm{m}^{-1}\right)$ & 0.185 & 0.175 & 0.342 & -0.162 & 0.508 \\
\hline $\mathrm{P}\left(\mathrm{mg} \mathrm{kg}^{-1}\right)$ & 0.204 & 0.031 & 0.222 & $\underline{0.496}$ & 0.673 \\
\hline $\mathrm{K}\left(\mathrm{mg} \mathrm{kg}^{-1}\right)$ & 0.215 & 0.106 & 0.038 & $\underline{0.555}$ & 0.738 \\
\hline OC (\%) & $\underline{0.327}$ & -0.099 & -0.129 & -0.133 & 0.887 \\
\hline $\mathrm{N}(\%)$ & $\underline{0.334}$ & -0.062 & -0.096 & -0.024 & 0.883 \\
\hline $\mathrm{Fe}\left(\mathrm{mg} \mathrm{kg}^{-1}\right)$ & 0.235 & -0.016 & 0.340 & 0.211 & 0.629 \\
\hline $\operatorname{Mn}\left(\mathrm{mg} \mathrm{kg}^{-1}\right)$ & $\underline{0.277}$ & -0.058 & -0.124 & 0.078 & 0.627 \\
\hline $\mathrm{Zn}\left(\mathrm{mg} \mathrm{kg}^{-1}\right)$ & $\underline{0.300}$ & -0.049 & -0.144 & -0.025 & 0.728 \\
\hline $\mathrm{Cu}\left(\mathrm{mg} \mathrm{kg}^{-1}\right)$ & $\underline{0.283}$ & 0.059 & 0.072 & -0.028 & 0.635 \\
\hline $\operatorname{MBC}\left(\mathrm{mg} \mathrm{kg}^{-1}\right)$ & $\underline{0.330}$ & -0.051 & -0.118 & -0.082 & 0.873 \\
\hline $\operatorname{PMN}\left(\mu \mathrm{gN} \mathrm{g}^{-1}\right)$ & 0.218 & -0.103 & 0.026 & -0.429 & 0.601 \\
\hline $\mathrm{AC}\left(\mathrm{mg} \mathrm{kg}^{-1}\right)$ & $\underline{0.251}$ & -0.186 & -0.081 & -0.122 & 0.581 \\
\hline Sand (\%) & 0.039 & 0.410 & $\underline{-0.556}$ & 0.150 & 0.766 \\
\hline Clay (\%) & 0.088 & $\underline{0.605}$ & 0.006 & -0.119 & 0.782 \\
\hline Silt (\%) & 0.070 & 0.369 & 0.408 & -0.249 & 0.709 \\
\hline $\operatorname{AWC}\left(\mathrm{cm}^{3} \mathrm{~cm}^{-3}\right)$ & $\underline{0.270}$ & -0.040 & -0.141 & -0.175 & 0.587 \\
\hline $\mathrm{BD}\left(\mathrm{Mg} \mathrm{m}^{-3}\right)$ & 0.100 & 0.436 & -0.162 & -0.022 & 0.479 \\
\hline
\end{tabular}

PC - principal component. Underlined factor loadings are considered highly weighted when within $10 \%$ of variation of the absolute values of the highest factor loading in each PC, and underlined factor loadings in bold type represent the soil properties selected as MDS.

on their correlation structure. Within each $P C$, the variable with the highest factor loading was selected as the most important contributor to the $\mathrm{PC}$ for $\mathrm{MDS}$. $\mathrm{PC}_{1}$ had the highest eigenvalue (7.742) and included more variables with similar factor loading than other PCs. Since $P C_{1}$ had no variable with loadings $>|0.40|$, the variables with loadings $\geq|0.25|$ were considered for better interpretation. In $\mathrm{PC}_{1}$, the highest weighted variables were $\mathrm{N}, \mathrm{OC}, \mathrm{Mn}, \mathrm{Zn}, \mathrm{Cu}, \mathrm{MBC}$, $\mathrm{AC}$ and AWC (Table 3). These variables were selected as effective indicators of soil quality changes resulting from management practices (Gugino et al., 2009). To reduce redundancy among the highly weighted variables for a particular PC, Pearson correlation coefficients and correlation sums were determined for each variable with high eigenvectors within $\mathrm{PC}_{1}$ (Table 4).

Soil $\mathrm{N}$ was the variable with the highest factor loading as the most important contributor to the $\mathrm{PC}_{1}$, hence it was selected for MDS. Thus, the variables with the highest correlation sum are considered to be the best representatives of the group. In this regard, $\mathrm{Zn}$ and $\mathrm{Mn}$ followed by $\mathrm{OC}$ and $\mathrm{Cu}$ had the highest correlation sum, but they were excluded from the MDS because of having high correlations with $\mathrm{N}$ and $\mathrm{MBC}$. MBC, AC and AWC had the lowest correlation sums, but only MBC was retained for the MDS and AWC and $\mathrm{AC}$ were eliminated as discussed earlier. $\mathrm{In} \mathrm{PC}_{2}$ and $\mathrm{PC}_{3}$, clay and sand percentages had the highest factor loadings and were chosen for the MDS. Both $\mathrm{K}$ and $\mathrm{P}$ were highly weighted variables in $\mathrm{PC}_{4}$. $\mathrm{K}$ was the variable with the highest factor loading and was included in MDS. P was selected as effective indicator of soil quality for MDS because of its availability in calcareous soils of dry land agriculture (Tunesi et al., 1999) and also its importance as soil quality indicator for soil quality index calculation in agricultural fields irrigated with treated wastewater (Andrews et al., 2002b). Lee et al. (2006) also introduced available $\mathrm{P}$ as effective soil quality indicator for a crop rotation system. Thus, any expert can employ the options to select or eliminate the indicators from the final MDS based 
T a b I e 4. Pearson correlation coefficients and their sums for each variable with high factor loadings for $\mathrm{PC}_{1}$

\begin{tabular}{lcccccccc}
\hline Variables & $\mathrm{OC}$ & $\mathrm{N}$ & $\mathrm{Mn}$ & $\mathrm{Zn}$ & $\mathrm{Cu}$ & $\mathrm{MBC}$ & $\mathrm{AC}$ & AWC \\
\hline $\mathrm{OC}$ & 1 & 0.859 & 0.879 & 0.929 & 0.860 & 0.766 & 0.863 & 0.869 \\
$\mathrm{~N}$ & 0.859 & 1 & 0.931 & 0.924 & 0.885 & 0.696 & 0.906 & 0.877 \\
$\mathrm{Mn}$ & 0.879 & 0.931 & 1 & 0.904 & 0.863 & 0.913 & 0.841 & 0.861 \\
$\mathrm{Zn}$ & 0.929 & 0.924 & 0.904 & 1 & 0.833 & 0.905 & 0.811 & 0.858 \\
$\mathrm{Cu}$ & 0.860 & 0.885 & 0.863 & 0.833 & 1 & 0.899 & 0.853 & 0.814 \\
$\mathrm{MBC}$ & 0.766 & 0.696 & 0.913 & 0.905 & 0.899 & 1 & 0.906 & 0.874 \\
$\mathrm{AC}$ & 0.863 & 0.906 & 0.841 & 0.811 & 0.853 & 0.906 & 1 & 0.791 \\
AWC & 0.869 & 0.877 & 0.861 & 0.858 & 0.814 & 0.874 & 0.791 & 1 \\
Correlation sum & 7.028 & 7.081 & 7.195 & 7.167 & 7.011 & 6.962 & 6.975 & 6.947 \\
\hline
\end{tabular}

Explanations as in Table 1.

a

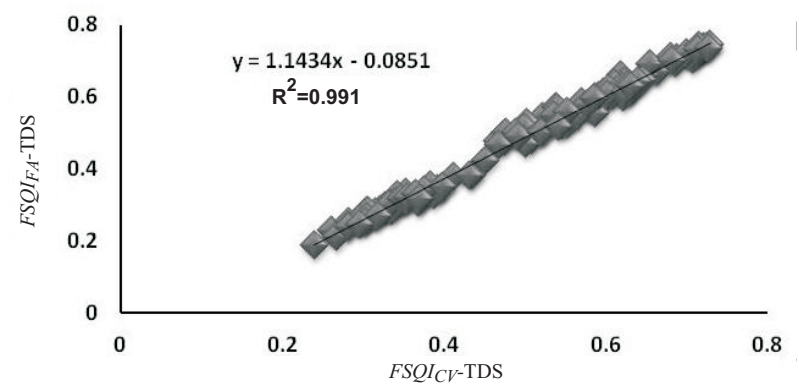

b

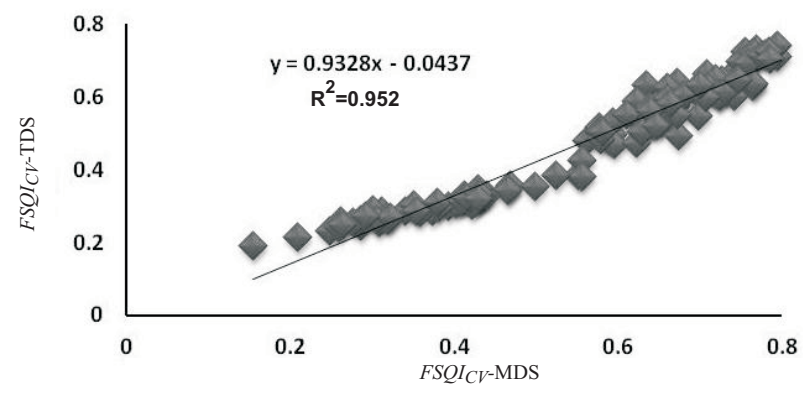

Fig. 2. Linear relationship between: a $-F S Q I_{F A}$-TDS and $F S Q I_{C V}$-TDS, b - FSQI $I_{C V}$-TDS and $F S Q I_{C V}$-MDS.

on their simplicity of sampling, measurement cost and interpretation of results (Dalal and Moloney, 2000). In summary, six variables, namely $\mathrm{N}, \mathrm{MBC}, \mathrm{P}, \mathrm{K}$, clay and sand percentage obtained from 4 PCs with eigenvalues above 1 were selected for MDS. Most of these soil quality indicators included are suggested by Doran and Parkin (1994). Therefore, the $P C A$ provide the choice of selecting effective indicators of soil quality as a minimum data set (MDS) from initial large total data sets (Govaerts et al., 2006). Based on communality values, PCA indicated that $\mathrm{OC}, \mathrm{N}$ and $\mathrm{MBC}$ with communality $(\mathrm{COM})>0.85$ and $\mathrm{pH}$ and $\mathrm{BD}$ with communality $(\mathrm{COM})<0.50$ are the most and the least important attributes, respectively (Table 3 ). Indeed, high communality estimates indicate higher share of variance explained by the variable (Johnson and Wichern, 1992), hence they should be preferred over variables with low communality estimate. The linear relationship between $F S Q I_{C V}$ and $F S Q I_{F A}$ for TDS indicator method $\left(\mathrm{R}^{2}=0.99\right)$ shows that $F S Q I_{C V}$ and $F S Q I_{F A}$ provide similar soil quality assessment in our study area (Fig. 2a). Since the computation of communality of each variable requires PCA that, theoretically, is more complicated than $\mathrm{CV}$ method, variables weighting by the coefficient of variation method $(\mathrm{CV})$ is more straightforward. Therefore, for the study of soil quality, $F S Q I_{C V}$ was replaced with $F S Q I_{F A}$ index. As shown in Fig. 2b, the linear regression of $F S Q I_{C V}$ between MDS and TDS sets was $\mathrm{R}^{2}=0.951$, confirming that MDS set is sufficient for soil quality assessment.

$F S Q I_{C V}$ was calculated for each aspect (soil chemical, biological and physical properties). Figure 3 illustrates the spatial and temporal variations in soil quality aspects affected by treated urban wastewater use. Soil physical quality index with mean value of $58 \%$ represented the moderate physical quality of studied soil. Virto et al. (2010) showed that the conventional farming systems had lower physical quality than other management systems. Soil biological quality increased dramatically following cultivation and use of treated urban wastewater. However, soil chemical quality index did not change significantly. Thus, monitoring soil biological indicators changes can be useful for farmers who plan to change management practices to improve soil quality (tillage reduction, use of new cover crops, addition of organic fertilizers).

Analysis of spatial dependence of soil quality indices showed an isotropic behaviour (Table 5). It is probably due to a low variability of soil formation factors as well as 
a

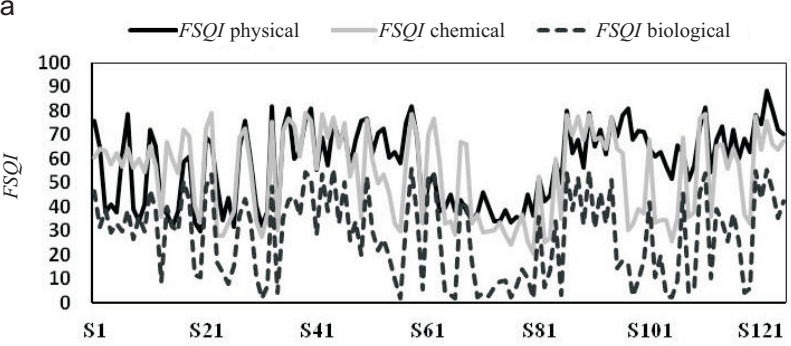

b
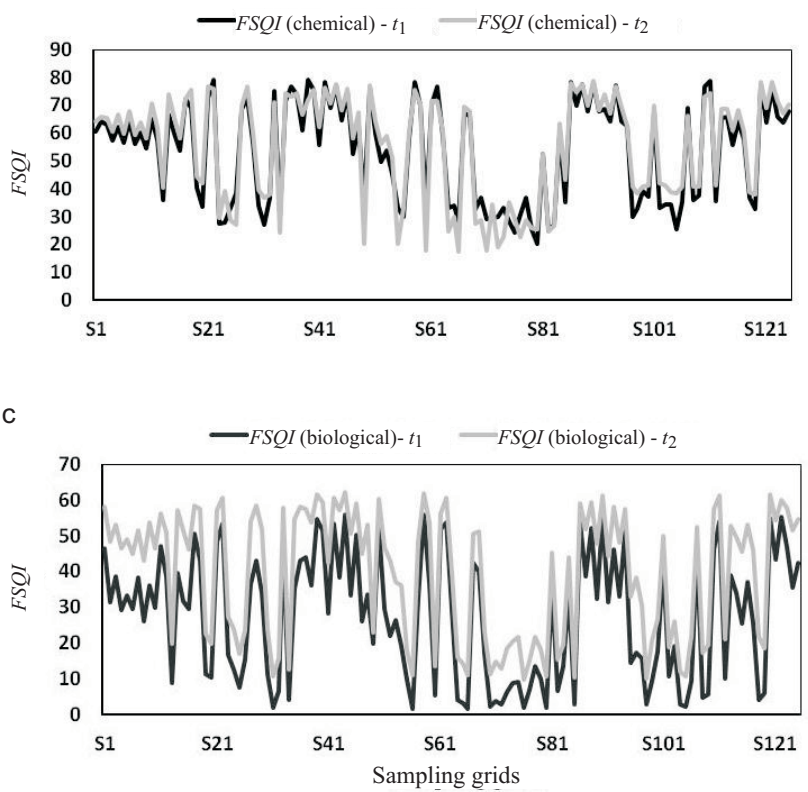

Fig. 3. Spatial and temporal variations in soil quality indices at two sampling times: a - FSQI-chemical, FSQI-biological and FSQIphysical for first time, b-FSQI-chemical, and c - FSQI-biological between two times.

soil management practices. Semivariogram models and best-fitted model parameters are presented in Table 5 and Fig. 4. Semivariograms were used to establish relation between spatial continuity and the range of spatial dependency. The experimental semivariogram shows the variance of sample values in different lag distances. $F S Q I_{C V}$ in two sampling times showed positive nugget, which could be a result of sampling error, short range variability, random and inherent variability (Trangmar et al., 1985). The nugget to sill ratio represents the spatial dependency of soil properties. Spatial dependency can be defined as strong, moderate, weak or pure nugget based on the nugget to sill ratio $<25$, $25-75,>75$, or $=100 \%$, respectively. It is considered as weak if the fitting $\mathrm{R}^{2}<0.50$ (Trangmar et al., 1985). The nugget to sill ratio showed a strong spatial dependence for FSQI $C V\left(t_{1}\right)\left(\mathrm{t}_{1}\right.$ : first soil sampling time before application of treated urban wastewater) which might be attributed to fallow condition before starting wheat-maize rotations. $\left.F S Q I_{C V} t_{2}\right)\left(t_{2}\right.$ : second soil sampling time after application of treated urban wastewater in 2nd year) were moderately spatially dependent imprinted by extrinsic factors such as soil cultivation and wastewater irrigation. Due to wastewater application, $F S Q I_{C V}$ lost the strong spatial dependence, which might be caused by a decrease in spatial dependency of soil indicators used in $F S Q I_{C V}$ calculation. The range of semivariogram for $F S Q I_{C V}\left(t_{2}\right)(75.7 \mathrm{~m})$ increased compared to $F S Q I_{C V}\left(t_{1}\right)(70.5 \mathrm{~m})$, thereby reflecting the influence of soil management practices, which might be due to uniform wastewater application compared to well water application and chemical fertilizer applied as an earlier management practice.

To explain vast differences in soil biological and chemical qualities, score changes in each indicator were examined in two time intervals (Fig. 5). Results showed that the improvement of soil biological quality is due to increased score of $\mathrm{MBC}, \mathrm{AC}$ and PMN. Cultivation and treated urban wastewater factors had minor effects on PMN as its mean value was much smaller than the optimum value $\left(15 \mu \mathrm{gN} \mathrm{g}^{-1} \mathrm{dw}\right.$ soil/week). PMN is interpreted as soil capacity to convert organic nitrogen into inorganic forms, and has a direct relationship with the amount of soil active and total organic carbon and aggregate stability. Hence, including legumes in crop rotation is useful strategy for increasing microbial biomass responsible for nitrogen mineralization (Gugino et al., 2009). The slight increase in soil chemical quality may be attributed to the soil copper score reduction and the slight increase in the amount of soil macronutrients after maize harvest, probably due to larger plant uptake. Soil copper concentration exceeded its optimum level, leading to a decrease in its score. However, no signs of copper toxicity were observed in maize, as copper concentration in plant

T a b l e 5. Parameters of the best-fitted variogram model for soil quality indices and their changes

\begin{tabular}{llcccccc}
\hline Variables & Model & Nugget $(\mathrm{CO})$ & $\begin{array}{c}\text { Sill } \\
(\mathrm{CO}+\mathrm{C})\end{array}$ & $\begin{array}{c}\text { Range effect } \\
(\mathrm{m})\end{array}$ & $\mathrm{R}^{2}$ & $\begin{array}{l}\text { Nugget/ } \\
\text { Sill }(\%)\end{array}$ & $\begin{array}{l}\text { Spatial } \\
\text { class }\end{array}$ \\
\hline FSQI $_{C V}\left(t_{1}\right)$ & Exponential & 39.30 & 312.00 & 70.50 & 0.91 & 12 & Strong \\
$F S Q I_{C V}\left(t_{2}\right)$ & Spherical & 98.30 & 332.40 & 75.70 & 0.97 & 29 & Moderate \\
$\Delta F S Q I$ & Spherical & 9.76 & 19.53 & 169.50 & 0.97 & 49 & Moderate
\end{tabular}

$F S Q I_{C V}\left(t_{1}\right), F S Q I_{C V}\left(t_{2}\right)$, and $\triangle F S Q I-$ fuzzy soil quality index at two soil sampling times and their changes. Explanations as in Table 2. 
a

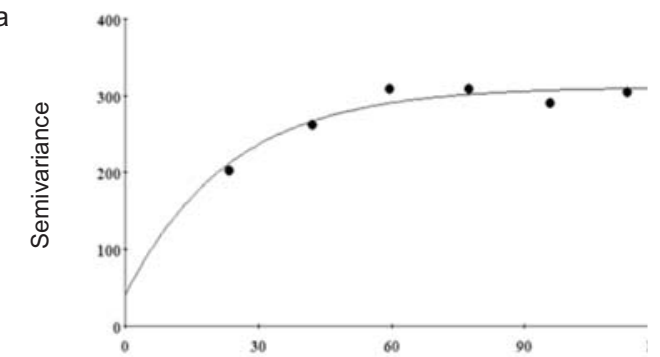

b

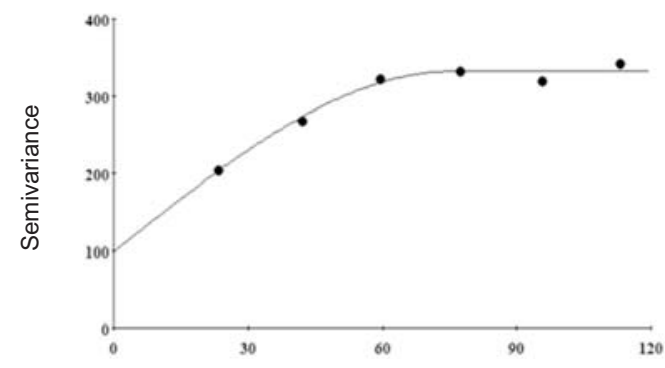

C

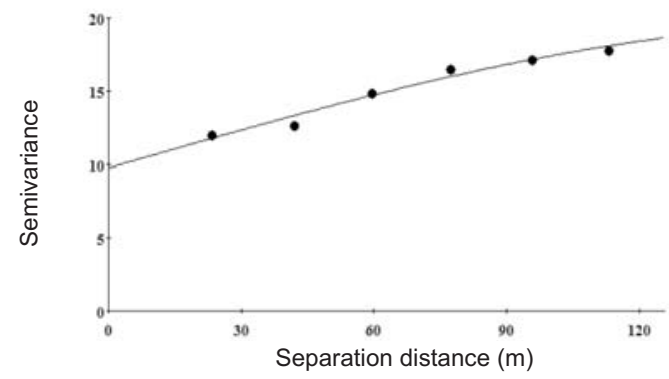

Fig. 4. Experimental semivariograms and the fitted models for Fuzzy soil quality index at: a, b - two soil sampling times, and c - their changes. samples was about $0.0032 \mathrm{mg} \mathrm{g}^{-1}$ dry matter (DM). This concentration may be attributed to the increased levels of soil available nitrogen and phosphorus resulting in decrease of $\mathrm{Cu}$ uptake by plant (Zhang and Raun, 2006).

For assessing soil quality, FSQI index was divided into five classes (I-V) (Gugino et al., 2009): grade I (FDQI> 85\%) and grade II ( $F D Q I: 70-85 \%)$ for fertile and relatively fertile soils for plant growth, grade III (FDQI: 55-70\%) for soils with medium quality having some limitations for plant growth, grade IV (FSQI: $40-55 \%)$ and grade V $(F D Q I<40 \%)$ as relatively infertile and infertile soils having high limitations for plant growth. According to this classification, the soils under study are included in classes II, III, IV and V based on $F S Q I_{C V}$. The kriging map of $F S Q I_{C V}$ in two sampling times showed that low quality soils (classes V and IV) were distributed in the middle part, southwest and southeast parts of the studied area. However, in second soil sampling after applying treated urban wastewater, low quality soils were changed into medium quality and high quality ones (classes III and II) (Fig. 6). At the first sampling time, percentages of soil samples in classes V, IV, III and II were 37.6, 17.6, 31.2, and $13.6 \%$, respectively. In the second sampling time, these proportions changed to $32,10.4,38.4$, and $19.2 \%$. Temporal changes of $F S Q I_{C V}$ among different sampling grids was about $5 \%$, with more improvement in soil quality of infertile and relatively infertile sites (5-11\%) compared to the relatively fertile and moderately fertile sites (1-4\%). Zhang et al. (2004) proposed that as soil is heterogeneous, the area can be divided into different zones with more homogeneous levels of soil quality. Thus, it can be concluded that $F S Q I_{C V}$ index can be used to identify various management zones based on spatial and temporal changes in soil quality and crop yield under field-scale (Fig. 6). In general, management practices in conventional systems involve the application of large amounts of inorganic fertilizers and pesticides, reduced use of organic amendments, continuous tillage and a

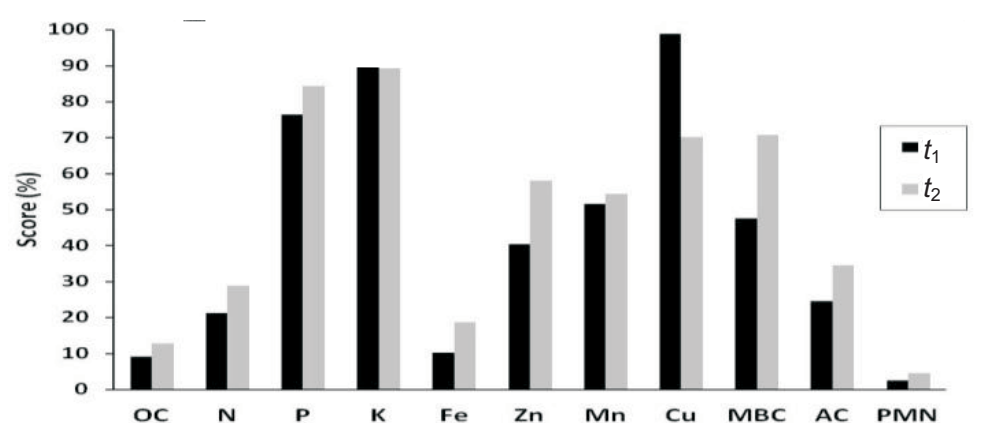

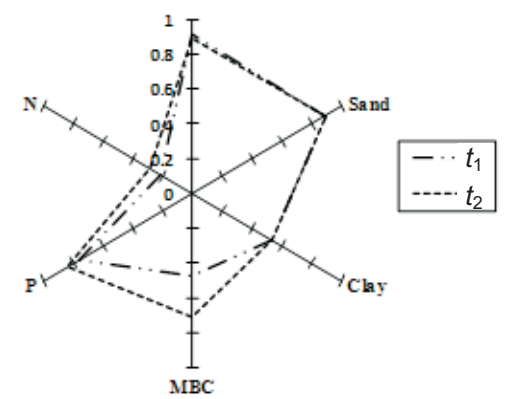

Fig. 5. Score changes of soil indicators between two sampling times for: $\mathrm{a}-\mathrm{TDS}$, and b-MDS. Explanations as in Table 1 . 
a
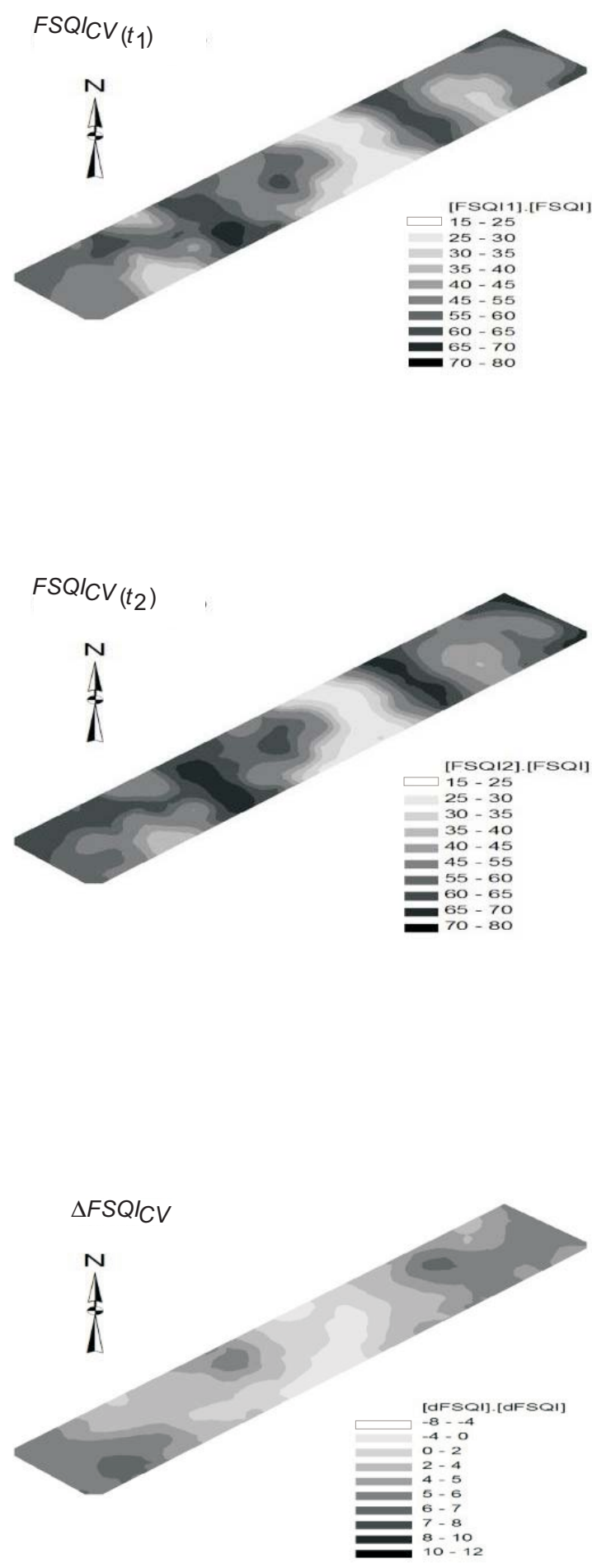

Fig. 6. Fuzzy soil quality index maps produced at: a, b - two soil sampling times, and $\mathrm{c}-$ their spatial-temporal changes. Explanations as in Table 2. a

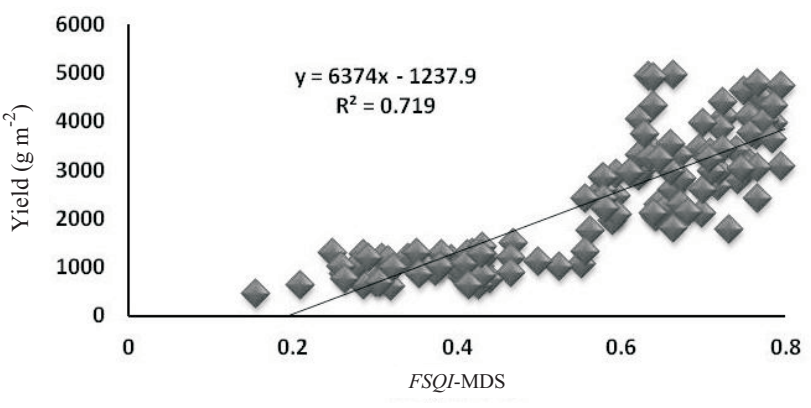

b

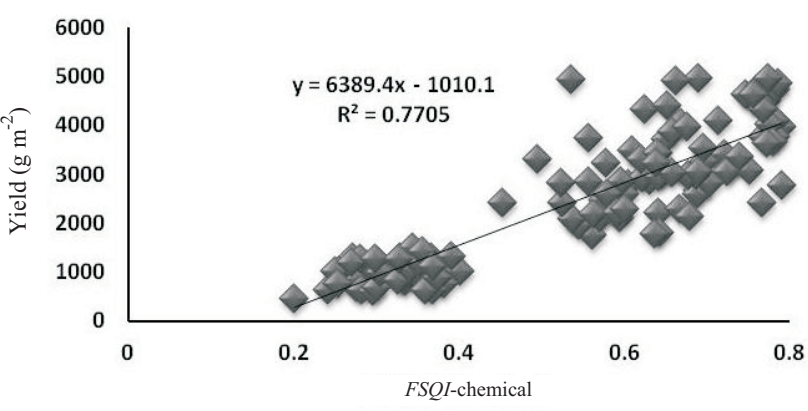

C
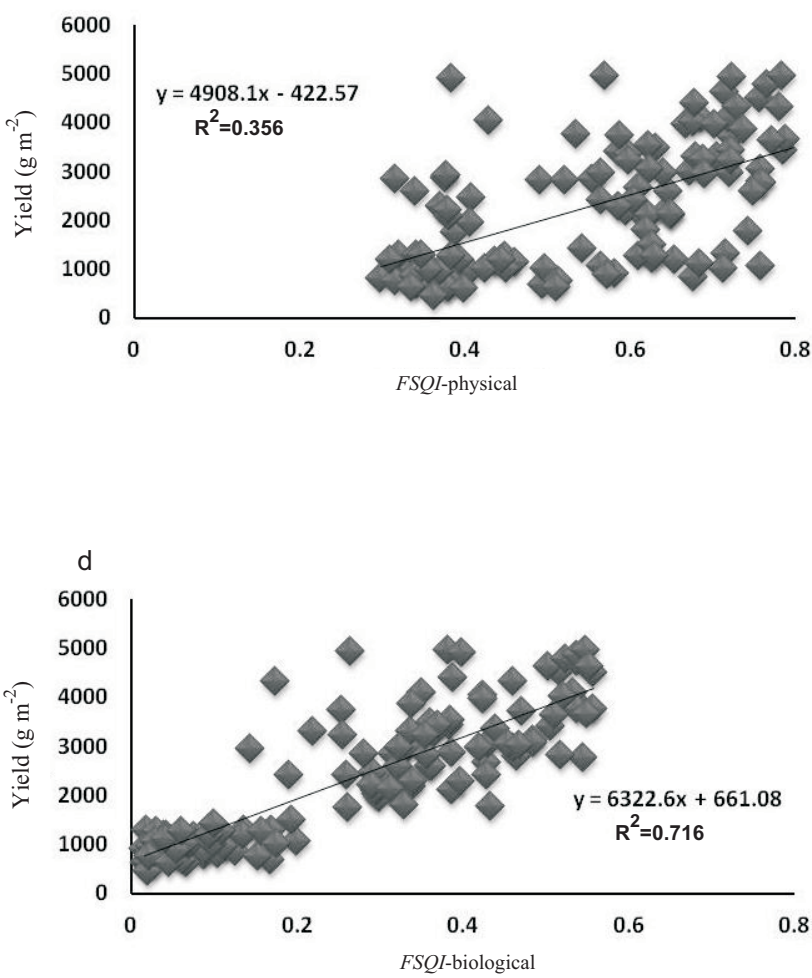

Fig. 7. Linear model fitted to the following pairs: a $-F S Q I_{M D S}$ and maize yield, b-FSQI $I_{C V}$ - chemical and maize yield, c $-F S Q I_{C V}-$ physical and maize yield, $\mathrm{d}-F S Q I_{C V}-$ biological and maize yield. 
irrigation, and mechanized harvesting (Huang et al., 2007). These practices decrease soil quality under dense cropping systems (Andrews et al., 2002b). Thus, the implementation of appropriate management strategies such as use of organic wastes, reduction of soil tillage, and inclusion of legumes in crop rotations, can partly improve soil consistency and its quality since crop residues addition will increase total soil nitrogen and organic matter, thereby directly affecting carbon and nitrogen accumulation in soil (Huang et al., 2007). To evaluate the effects of soil quality index on yield, relationships between soil chemical, biological and physical aspects of soil quality and maize yield were evaluated (Fig. 7).

The results showed that $F S Q I_{C V}$ explains significantly the large proportion $\left(\mathrm{R}^{2}=0.72\right)$ of the within-field yield variability (Fig. 7a), suggesting that soil quality can reflect the crop yield potential (Shukla et al., 2006). Similar correlation levels were observed for soil chemical and biological indices of soil quality. Therefore, the quality indices of soil chemistry $\left(R^{2}=0.77\right)$ and soil biology $\left(R^{2}=0.72\right)$ were the highest. Relationship between maize yield and physical quality index was much weaker $\left(\mathrm{R}^{2}=0.355\right)$. Thus, management changes in chemical and biological aspects resulted in more changes in yield.

\section{CONCLUSIONS}

1. The results of this study showed that the relationships between soil factors and land productivity may be well evaluated by fuzzy mathematical methods. Fuzzy soil quality index provides the proper interpretations of soil quality as a grade of perfection associated with uncertainties adjustment and filtration. The method has a high potential for monitoring the effects of soil management changes over time.

2. Principal component analysis facilitates the selection of soil biological, chemical, and physical properties to derive soil quality index and monitor the effects of management practices on soil functions. The use of minimum data set could save time and costs associated with the computation of these indices.

3. Variables weighting determined by the coefficient of variation method provides a straightforward way to combine soil properties in assessing soil quality.

4. Furthermore, treated urban wastewater may be used to improve soil quality, but it is essential to evaluate the spatial and temporal variability of soil quality as a result of heavy metals accumulation and crop yield reduction in long term.

5. The combination of fuzzy sets and ordinary kriging indicated considerable spatial variations in soil quality at field scale. Although, in general, soil quality indices definition based on physical, chemical and biological indicators can provide a comprehensive understanding of management strategies affecting soil quality in long time, but this is a first trial of creation of a universal index of soil quality undertaken in this study.

\section{REFERENCES}

Andrews S.S. and Carroll C.R., 2001. Designing a soil quality assessment tool for sustainable agroecosystem management. Ecological Applications, 11, 1573-1585.

Andrews S.S., Mitchell J.P., Mancinelli R., Larlen D.L., Hartz T.K., Horwarth W.R., Pettygrove G.S., Scow K.M., and Munk D.S., 2002b. On farm assessment of soil quality in California Central Valley. J. Agronomy, 94, 12-23.

Aparicio V. and Costa J.L., 2007. Soil quality indicators under continuous cropping systems in the Argentinean pampas. Soil Till. Res., 96, 155-165.

Braimoh A.K., Vlek P.G., and Stein A., 2004. Land evaluation for maize based on fuzzy set and interpolation. Environ. Manag., 33(2), 226-238.

Dalal R.C. and Moloney D., 2000. Sustainability indicators of soil health and biodiversity. In: Management for Sustainable Ecosystems, Centre for Conservation Biology (Eds P. Hale, A. Petrie, D. Moloney, P. Sattler). University of Queensland, Brisbane, Australia.

Doran J.W. and Parkin T.B., 1994. Defining and assessing soil quality. In: Defining soil quality for a sustainable environment (Eds J.W. Doran et al.). SSSA Press, Madison, WI, USA.

Feizi M., 2001. Effect of treated wastewater on accumulation of heavy metals in plants and soil. ICID Int. Workshop Wastewater Reuse Management, September 19-20, Seoul, South Korea.

Klute A. (Ed.), 1986. Methods of Soil Analysis. Part 1. Physical and Minerological Methods. ASA, SSSA, Madison, WI, USA.

Glover J.D., Reganold J.P., and Andrews P.K., 2000. Systematic method for rating soil quality of conventional, organic and integrated apple orchards in Washington State. Agric., Ecosystems Environ., 80, 29-45.

Govaerts B., Sayre K.D., and Deckers J., 2006. A minimum data set for soil quality assessment of wheat and maize cropping in the highlands of Mexico. Soil Till. Res., 87, 163-174.

Gugino B.K., Idowu O.J., Schindelbeck R.R., vanEs H.M., Wolfe D.W., MoebiusClune B.N., Thies J.E., and Abawi G.S., 2009. Cornell Soil Health Assessment Training Manual, Edition 2.0, Cornell University, Geneva, NY, USA.

Hao X., Ball B.C., Culley J.L.B., Carter M.R., and Parkin G.W., 2008. Soil density and porosity. In: Soil Sampling and Methods of Analysis (Eds M.R. Carter, E.G. Gregorich). Canadian Soil Sci. Soc., Taylor and Francis Press, Boca Raton, FL, USA.

Hazelton P. and Murphy B., 2007. Interpreting Soil Test. Results: What do all the numbers mean? CSIRO Press, Melbourne, Australia.

Huang B., Sun W.X., Zhao Y.C., Zhu J., Yang R.Q., Zou Z., Ding F., and Su J.P., 2007. Temporal and spatial of soil organic matter and total nitrogen in an agricultural ecosystem as affected by farming practices. Geoderma, 139, 336-345.

Johnson R.A. and Wichern D.W., 1992. Applied multivariate statistical analysis. Prentice-Hall, Englewood Cliffs, NJ, USA. 
Lee C.H., Wu M.Y., Asio V.B., and Chen Z.S., 2006. Using a soil quality index to assess the effects of applying swine manure compost on soil quality under a crop rotation system in Taiwan. Soil Sci., 171(3), 210-222.

Lindsay W.L. and Norvell W.A., 1978. Development of a DTPA soil test for zinc, iron, manganese and copper. Soil Sci. Soc. America J., 42, 421-428.

Malakouti M.J. and Tehrani M.M., 1999. Effects of micronutrients on the yield and quality of agricultural products (micro nutrients with macro effects) (in Persian). Tarbiat Modarres University Press, Tehran, Iran.

Mallarino A.P., Wittry D.J., and Barbagelata P.A., 2003. New soil test interpretation classes for potassium. Better Crops, 87(4), 12-14.

Masto R.E., Chhonkar P.K., Singh D., and Patra A.K., 2007. Soil quality response to long-term nutrient and crop management on a semi-arid inceptisol. Agric. Ecosystems Environ., $118,130-142$.

Mathworks Inc., 2004. http://www.mathworks.com

McBratney A.B. and Odeh I.O., 1997. Application of fuzzy sets in soil science: fuzzy logic, fuzzy measurements and fuzzy decisions. Geoderma, 77, 85-113.

Mohammadrezaei M., Fathi M., and Attarzadeh N., 2012. Proposing a new approach to applying pervasive computing in agriculture environments. Int. J. Comput. Sci. Net. Sec. Int. J. Computer Sci. Network Security, 12(8), 55-59.

Page A.L., Miller R.H., and Keeney D.R., 1982. Methods of Soil Analysis. Part 2. Chemical and microbiological properties. ASA SSSA, Madison, WI, USA.

SafarySanjany A.A. and Hajrasoliha S., 1995. Effects of North Isfahan sewage effluent on the soils of Borkhar region and composition of alfalfa. 5th Soil Sci. Congress, Agricultural Vocational School, September, Karaj, Iran.

Shukla M.K., Lal R., and Ebinger M., 2006. Determining soil quality indicators by factor analysis. Soil Till. Res., 87, 194-204.

Tisdale S.L., Nelson W.L., Beaton J.D., and Havlin J.L., 1993. Soil fertility and fertilizers. MacMillan Publishing Co., New York, NY, USA.

Torbert H.A., Krueger E., and Kurtener D., 2008. Soil quality assessment using fuzzy modeling. Int. Agrophysics, 22, 365-370.
Trangmar B.B., Yost R.S., and Uehara G., 1985. Application of geostatistics to spatial studies of soil properties. Advances Agron., 38, 45-94.

Tunesi S., Poggi V., and Gessa C., 1999. Phosphate adsorption and precipitation in calcareous soils: the role of calcium ions in solution and carbonate minerals. Nutrient Cycling Agroecosys., 53, 219-227.

Vance E.D., Brookes P.C., and Jenkinson D.S., 1987. An extraction method for measuring soil microbial biomass carbon. Soil Biol. Biochem., 19(6), 703-707.

Virto I., Imaz M.J., Mijangos I., Hernández-Allica J., FernándezUgalde O., Garbisu C., Bescansa P., and Enrique A., 2010. Soil quality in a semi-arid Mediterranean soil as affected by tillage system and residue burning. 19th World Congr. Soil Sci., Soil Solutions for a Changing World, August 1-6, Brisbane, Australia.

Walkely A. and Black I.A., 1934. An examination of the Degtjareff method for determining soil organic matter and a proposed modification of the chromic acid titration method. Soil Sci., 37, 29-38.

Wilding L.P., 1985. Spatial variability its documentation, accommodation and implication to soil survey. In: Soil Spatial Variability (Eds D.R. Nielsen, J. Bouma). Pudoc, Wageningen, the Netherlands.

Yang L., Zhu A.X., Li B.L., Qin C.Z., Pei T., Liu B.Y., Li R.K., and Cai Q.G., 2007. Extraction of knowledge about soil environment relationship for soil mapping using fuzzy c-means (FCM) clustering. Acta Pedologica Sinica, 44, 16-23.

Zadeh L.A., 1965. Fuzzy sets. Inform. Control, 8(6), 338-353.

Zalidis G., Stamatiadis S., Takavakoglou V., Eskridge K., and Misopolinos N., 2002. Impacts of agricultural practices on soil and water quality in the Mediterranean region and proposed assessment methodology. Agric. Ecosystems Environ., 88(2), 137-146.

Zhang B., Zhang Y., Chen D., White R.E., and Li Y., 2004. A quantitative evaluation system of soil productivity for intensive agriculture in China. Geoderma, 123, 319-331.

Zhang H. and Raun B., 2006. Soil Fertility. Handbook Department of Plant and Soil Sciences, Oklahoma State University, Stillwater, OK, USA. 